\section{Australian Journal of \\ Crop Science}

AJCS

ISSN:1835-2707

AJCS 13(01):35-44 (2019)

doi: 10.21475/ajcs.19.13.01.p1109

\title{
Identification of agronomical and morphological traits contributing to drought stress tolerance in soybean
}

\author{
Willian Giordani ${ }^{1}$, Leandro Simões Azeredo Gonçalves ${ }^{1}$, Larissa Alexandra Cardoso Moraes ${ }^{2}$, Leonardo \\ Cesar Ferreira ${ }^{3}$, Norman Neumaier ${ }^{2}$, José Renato Bouças Farias ${ }^{2}$, Alexandre Lima Nepomuceno ${ }^{2}$, Maria \\ Cristina Neves de Oliveira ${ }^{2}$, Liliane Marcia Mertz-Henning ${ }^{2^{*}}$
}

${ }^{1}$ Londrina State University, Londrina, PR, Brazil

${ }^{2}$ Embrapa Soja, Londrina, PR, Brazil

${ }^{3} \mathrm{CNPq} /$ Embrapa Soja, Londrina, PR, Brazil

*Corresponding author: liliane.henning@embrapa.br

\begin{abstract}
Abiotic stresses, especially drought, may seriously affect soybean yield. Due to the complexity of drought tolerance, one of the difficulties in selecting genotypes is the identification of traits contributing to improve stress tolerance. This study carried out soybean phenotyping under water deficit in vegetative and reproductive stages in field conditions at two consecutive crop seasons (2012/13 and 2013/14). The experiment was performed in Londrina, PR, Brazil, with two soybean cultivars with distinct levels of drought tolerance, BR 16 (sensitive) and Embrapa 48 (less sensitive). Water deficit was applied through rainout shelters, moving on rails to cover plots when the rainfall begins and uncover them when it ends. Then, some agronomic and morphological traits were measured. Multivariate statistics through the principal component analysis (PCA) associated with the biplot graph identified traits contributing to greater yield stability under drought. Result showed that water deficit affected soybean yield, mainly in the reproductive stage, in which Embrapa 48 had greater yield stability when compared to BR 16 . However, opposite results were obtained for stress induced in the vegetative stage, when Embrapa 48 was more negatively affected than BR16 cultivar. Seed weight influenced yield differences between cultivars. Lighter seeds, but in larger number, constituted an advantage under water deficit. Due to the difficulty in introducing all drought tolerance mechanisms in one genotype, breeding programs need to define selection parameters according to regional drought conditions.
\end{abstract}

Keywords: Glycine max L. Merrill; grain yield; plant growth; principal component analysis; water deficit.

Abbreviations: ANOVA_analysis of variance; DRL_dystrophic Red Latosol; DSI_drought susceptibility index; HI_apparent harvest index; HSW_100-seed weight; IPCC_Intergovernmental Panel on Climate Change; IRR_irrigated; LA_leaf area; LAI_leaf area index; LDM_leaf dry matter; NDVI_Normalized Difference Vegetation Index; NDVIV6_NDVI readings in the V6 stage; NDVIR3_NDVI readings in the R3 stage; NIRR_non-irrigated; NN_number of nodes; NPNS_number of pods with no seeds; NPS_number of pods with seeds; NS_number of seeds; PCs_principal components; PCA_principal component analysis; PH_plant height; SHDM_shoot dry matter; SVD_singular value decomposition; WDR_water deficit induced in the reproductive stage; WDV_water deficit induced in the vegetative stage.

\section{Introduction}

Soybean (Glycine max L. Merrill) is the most important oleaginous crop worldwide and occupies an area of approximately 118 million hectares, with production of around 320 million tons (USDA, 2016). Brazil is the second largest producer of soybean in the world and, besides supplying the internal market, the surplus volume represents the main Brazilian export agricultural product.

Despite such expressive numbers, soybean crop yield and geographic distribution can be severely limited by restrictions imposed by biotic and abiotic factors to which plants are exposed. Among abiotic factors, drought has been one of the main factors responsible for crop shortfalls in world agriculture, leading to drastic reductions in yield and in seed and grain quality (Wu et al., 2011; Khalili et al., 2013; $\mathrm{Ku}$ et al., 2013). Water deficit affects physiological and agronomic traits of soybean plants, thus negatively influencing plant growth and development, resulting in grain yield reduction (Stolf-Moreira et al., 2010).

The importance of studies on management improvement techniques and the development of tolerant plants become more evident when considering the Intergovernmental Panel on Climate Change (IPCC) reports (IPCC, 2014), which presented detailed information on increases in the levels of greenhouse gases in the atmosphere due to the anthropic interference and their impact on the weather worldwide. Scientific forecasts draw a future with dark scenarios of water restrictions around the world (Dai, 2013).

Water deficit effects on soybean yield depend on intensity, duration and period of its occurrence. When drought occurs on the first vegetative development stage, soybean plants have greater recovery capacity and may tolerate short periods of water deficit. However, sensitivity to stress tends 
to increase as the crop develops, with a maximum degree in the reproductive stage (Kron et al., 2008; Rolla et al., 2014).

Due to the complexity of plant responses to water deficit, the search for more drought tolerant cultivars has been a hard task, so that phenotyping and identification of traits contributing to select the best genotypes under water deficit conditions represent the main challenges in this process. Thus, a detailed characterization of soybean plants under drought conditions may indicate traits contributing to greater yield stability, thus helping in the selection of tolerant plants.

The aim of the present study was to identify agronomic and morphological traits contributing to yield stability in two soybean cultivars (with different sensitivity to drought) submitted to water deficit in vegetative and reproductive stages under field conditions at two consecutive crop seasons.

\section{Results}

\section{Climate conditions and Stress Index}

Water balance showed great variation between crop seasons (Figures S1A and S1B). The 2012/13 season was characterized by the occurrence of well-distributed rainfall, while the $2013 / 14$ one was marked by severe water deficit between the second ten-day period of January and the second ten-day period of February, coinciding with the reproductive stage of soybean plants. Such a climate variation between both seasons led to a more severe water deficit stress in the second period of evaluation, according to the stress index data (Fischer and Maurer, 1978) ( Figure 1).

\section{Effect of water deficit agronomical and morphological parameters}

For the 2012/13 crop season, ANOVA showed significant stress effect for the variables NDVIV6, NDVIV3, LAI, SHDM, NPS, NS, HSW, HI, and yield, and significant cultivar effect for NDVIV6, NN, NPS, and HSW (Table 1). A significant interaction (water condition $\mathrm{x}$ cultivar) was detected for NDVIV6, NPS, HSW, HI, and yield.

In the 2013/14 crop season, the stress effect was significant for most parameters, except for NN and NPS, while the cultivar effect showed significance only for PH, LA, NPS, and yield. The interaction between water condition and cultivar was only significant for $\mathrm{PH}$ (Table 1 ).

Regarding growth parameters in the 2012/13 crop season, the different water conditions had no effect on NDVI in the V6 stage (NDVIV6) for the cultivar BR 16. However, the cultivar Embrapa 48 was affected by the treatment WDV. Consequently, NDVIV6 was greater for BR 16 than Embrapa 48 under WDV (Table 2).

For $\mathrm{PH}$, stress effect was only detected in the 2013/14 crop season, and only for the cultivar Embrapa 48 (Table 2), in which NIRR, WDV, and WDR water conditions showed reduction in $\mathrm{PH}$ when compared to IRR, thus indicating that such a variable was not the key contributing factor to the effects observed in grain yield.

For NN, in the 2012/13 crop season, BR 16 plants had higher values than those of Embrapa 48 (Table 3). In the 2013/14 crop season, however, no differences were detected regarding NN among water conditions or between cultivars (Table 4).

Under more favorable climate conditions $(2012 / 13)$, the traits LA, LAI, and LDM showed no significant differences for water conditions, genotypes or their interaction (Table 3). However, in the 2013/14 crop season, i.e. under more severe stress, both cultivars presented lower LAI and LDM when submitted to WDV. In addition, regardless of the treatments, the cultivar BR 16 showed greater LA than that of Embrapa 48 in such a crop season (Table 4).

For SHDM, in both seasons, the lowest values were obtained under WDR and WDV (Tables 3 and 4).

Regarding yield-related components, WDV and WDR led to the lowest values for NPS in the 2012/13 crop season (Table 2). In $2013 / 14$, no differences were detected among water conditions. However, in general, the cultivar Embrapa 48 had larger NPS than that of BR 16 regardless of the water condition (Table 4).

Water deficit (WDV and WDR) negatively affected NS (Tables 3 and 4). For HWS, BR 16 plants showed greater values than those of the cultivar Embrapa 48 (Tabela 2). However, for presenting heavier seeds, BR 16 was more affected by water deficit than Embrapa 48 during WDR (Table 2). In the 2013/14 crop season, i.e. under more severe stress, lower HWS values were detected under WDR. In addition, although no differences were detected for NPS, NS almost halved under WDR (Table 4).

As to grain yield, in 2012/13, the cultivar BR 16 was more sensitive to WDR than Embrapa 48. On the other hand, Embrapa 48 plants were more sensitive to WDV than BR 16 ones (Table 2). In 2013/14, i.e. under more severe stress, although no interaction was detected between water conditions and cultivars, higher values were observed for Embrapa 48 when compared to BR 16 plants regardless of the water condition (Table 4). Furthermore, in comparison with the previous crop season, lower yield was observed for both cultivars (Tables 2 and 4).

DSI (Fischer and Maurer, 1978) indicated different levels of susceptibility to drought between cultivars, showing that BR 16 plants were more sensitive to WDR, while Embrapa 48 was more sensitive to WDV (Figure 2).

\section{Principal component analysis}

The Pearson correlation coefficient (Figure 3 ) showed the lowest and the highest values for $\mathrm{HI} \times \mathrm{PH}(\mathrm{r}=-0.53)$ and NS $\times$ NPS ( $r=0.97)$. Among all evaluated variables, considering treatments, cultivars, and evaluation periods, NDVIR3, LA, LAI, LDM, SHDM, NPS, NS, HSW, and HI showed significant positive correlation with yield.

PCA was performed per cultivar as shown in polygonal biplots (Figures $4 \mathrm{~A}$ and $4 \mathrm{~B}$ ), as well as through their joint analysis (Figure $4 \mathrm{C}$ ). All analyses considered the two PCs corresponding to the two eigenvalues with the highest values, which, in all cases, explained more than $77 \%$ variance.

Figures $4 \mathrm{~A}$ and $4 \mathrm{~B}$ show a greater variance explained by the PC1 for variances associated with yield components in both cultivars. On the other hand, PC2 could better explain growth traits such as NDVI6, NN, and PH due to a high effect of WDV. 
Table 1. Analysis of variance (ANOVA) with mean squares for different sources of variation.

\begin{tabular}{|c|c|c|c|c|c|c|c|c|c|c|c|c|c|}
\hline \multicolumn{14}{|c|}{$2012 / 2013$} \\
\hline Source of Variation & NDVIV6 & NDVIR3 & $\mathrm{PH}$ & $\mathrm{NN}$ & LA & LAI & LDM & SHDM & NPS & NS & HSW & $\mathrm{HI}$ & YIELD \\
\hline Blocks & 0.000986 & 0.000155 & 174.023 & 1.5921 & 101235 & 2.7753 & 0.84623 & 21.86 & 86.64 & 166 & 1.021 & 0.000513 & 41327 \\
\hline Stress & $0.008138^{*}$ & $0.000912^{*}$ & 238.011 & 0.0871 & 90447 & $7.2455^{*}$ & 2.61003 & $396.63^{*}$ & $1667.07 *$ & 7695.5* & $15.032^{*}$ & $0.037887 *$ & 7130213* \\
\hline Error A & 0.001478 & 0.000049 & 77.196 & 1.1513 & 52200 & 1.6717 & 0.84449 & 12.74 & 56.17 & 159.1 & 0.918 & 0.001871 & 273061 \\
\hline Cultivar & $0.003741^{*}$ & 0.000021 & 193.061 & $15.68^{*}$ & 89507 & 1.3184 & 1.12875 & 17.62 & $887.26 *$ & 991.2 & $59.569 *$ & 0.002046 & 22934 \\
\hline Interaction & $0.002786^{*}$ & 0.000135 & 148.349 & 0.8925 & 110125 & 0.6135 & 1.37957 & 57.49 & $414.79 *$ & 1668.5 & $5.086^{*}$ & 0.0019* & $342953^{*}$ \\
\hline Error B & 0.000639 & 0.000045 & 46.976 & 0.3944 & 69865 & 1.2050 & 0.98390 & 27.53 & 111.24 & 528.3 & 0.547 & 0.000540 & 52851 \\
\hline CV1 & $4.75 \%$ & $0.79 \%$ & $15.10 \%$ & $7.47 \%$ & $17.16 \%$ & $24.98 \%$ & $18.79 \%$ & $17.42 \%$ & $17.71 \%$ & $15.06 \%$ & $7.48 \%$ & $8.24 \%$ & $15.25 \%$ \\
\hline $\mathrm{CV} 2$ & $3.13 \%$ & $0.75 \%$ & $11.78 \%$ & $4.37 \%$ & $19.86 \%$ & $21.20 \%$ & $20.26 \%$ & $25.61 \%$ & $24.92 \%$ & $27.44 \%$ & $5.77 \%$ & $4.43 \%$ & $6.72 \%$ \\
\hline \multicolumn{14}{|c|}{$2013 / 2014$} \\
\hline Source of Variation & NDVIV6 & NDVIR3 & $\mathrm{PH}$ & NN & LA & LAI & LDM & SHDM & NPS & NS & HSW & $\mathrm{HI}$ & YIELD \\
\hline Blocks & 0.000023 & 0.000764 & 67.63 & 0.62139 & 35262 & 0.43 & 0.4077 & 23.135 & 275.53 & 366.62 & 1.1206 & 0.001727 & 179573 \\
\hline Stress & $0.004841^{*}$ & $0.044144^{*}$ & $754.87^{*}$ & 0.45241 & $1015514 *$ & $17.4623^{*}$ & $7.6622^{*}$ & $144.99 *$ & 394.18 & $2155.93 *$ & $17.8164 *$ & $0.032121 *$ & $4585657^{*}$ \\
\hline Error A & 0.000457 & 0.001457 & 53.34 & 0.51723 & 54307 & 1.7818 & 0.5895 & 11.980 & 127.71 & 226.14 & 1.0737 & 0.001720 & 65321 \\
\hline Cultivar & 0.000114 & 0.000497 & $338.14 *$ & 0.05648 & $342130 *$ & 3.3829 & 0.7564 & 9.574 & $446.42 *$ & 382.49 & 0.4384 & 0.000283 & $1458444 *$ \\
\hline Interaction & 0.000301 & 0.00051 & $246.46^{*}$ & 1.51917 & 145411 & 0.4763 & 1.2212 & 3.471 & 71.24 & 109.18 & 1.864 & 0.002818 & 31094 \\
\hline Error B & 0.000625 & 0.000339 & 32.02 & 0.60544 & 59163 & 0.7254 & 0.9768 & 6.503 & 46.32 & 108.59 & 0.9123 & 0.000882 & 34729 \\
\hline CV1 & $2.57 \%$ & $4.79 \%$ & $9.57 \%$ & $4.82 \%$ & $21.86 \%$ & $30.03 \%$ & $20.11 \%$ & $21.88 \%$ & $35.50 \%$ & $23.19 \%$ & $10.88 \%$ & $10.68 \%$ & $13.27 \%$ \\
\hline $\mathrm{CV} 2$ & $3.00 \%$ & $2.31 \%$ & $7.41 \%$ & $5.21 \%$ & $22.81 \%$ & $19.16 \%$ & $25.88 \%$ & $16.12 \%$ & $21.38 \%$ & $16.07 \%$ & $10.03 \%$ & $7.65 \%$ & $9.68 \%$ \\
\hline
\end{tabular}

number of seeds; $\mathrm{HSW}$ - 100-seed weight; $\mathrm{HI}$ - apparent harvest index; Yield.

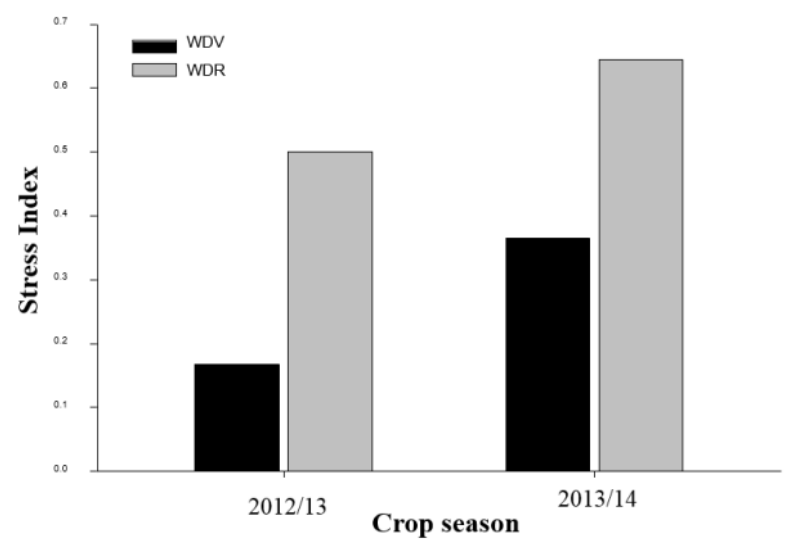

Fig 1. Stress Index according to Fischer e Maurer (1978), in soybean plants under water deficit induced in vegetative (WDV) and reproductive (WDR) stages, in 2012/13 and 2013/14 crop seasons. Londrina, PR, Brazil. 
Table 2. Morphological traits and yield components in the soybean cultivars Embrapa 48 and BR 16 under different water deficit conditions in the $2012 / 13$ and 2013/14 crop seasons. Londrina, PR. Variables with significant interaction (Cultivar $x$ Water Condition).

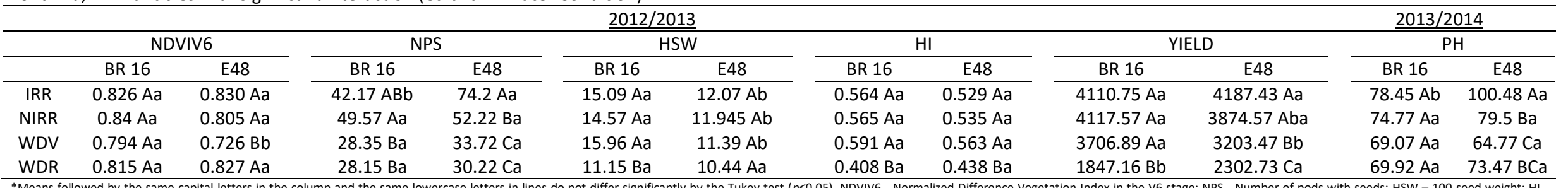

apparent harvest index Yield PH - plonteght.

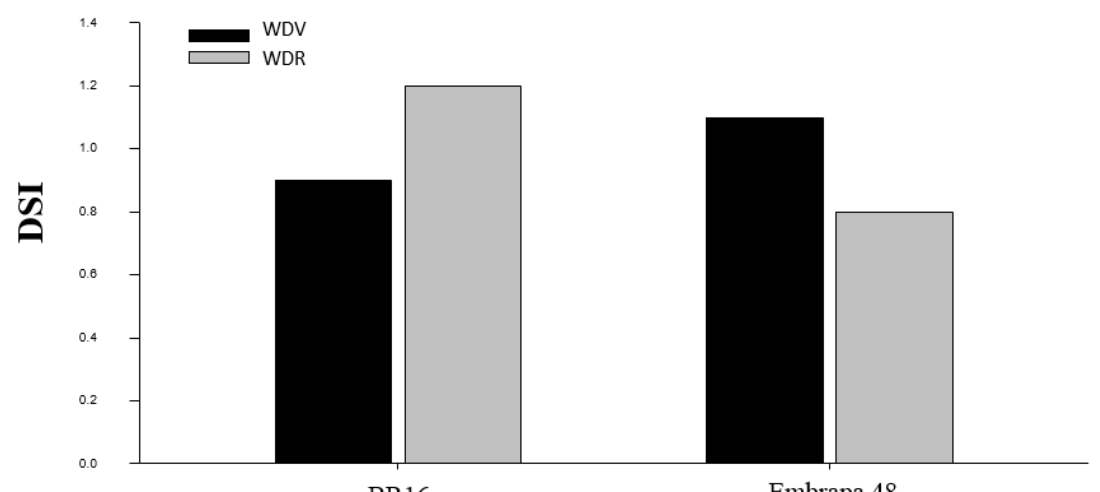

Cultivars

Fig 2. Drought Susceptibility Index (DSI), according to Fischer e Maurer (1978), in the soybean cultivars BR 16 and Embrapa 48, under water deficit induced in vegetative (WDV) and reproductive (WDR) stages.

Table 3. Morphological traits and yield components in the soybean cultivars Embrapa 48 and BR 16 under different water deficit conditions in the $2012 / 13$ crop season. Variables with no significant interaction (Cultivar $x$ Water Condition).

\begin{tabular}{|c|c|c|c|c|c|c|c|c|c|}
\hline \multicolumn{10}{|c|}{$2012 / 2013$} \\
\hline Water Condition & NDVIR3 & $\mathrm{PH}$ & NN & LA & LAI & NPNS & LDM & SHDM & NS \\
\hline IRR & $0.900 \mathrm{~A}$ & $62.15 \mathrm{~A}$ & $14.35 \mathrm{~A}$ & $1347.025 \mathrm{~A}$ & $6.266 \mathrm{~A}$ & $2.775 \mathrm{~A}$ & $5.21 \mathrm{~A}$ & $27.69 \mathrm{~A}$ & $117.96 \mathrm{~A}$ \\
\hline NIRR & $0.896 \mathrm{~A}$ & $57.56 \mathrm{~A}$ & $14.35 \mathrm{~A}$ & $1427.925 \mathrm{~A}$ & $5.673 \mathrm{~A}$ & $3.187 \mathrm{~A}$ & $5.18 \mathrm{~A}$ & $25.32 \mathrm{~A}$ & $101.67 \mathrm{~A}$ \\
\hline WDV & $0.883 \mathrm{~B}$ & $50.69 \mathrm{~A}$ & $14.2625 \mathrm{~A}$ & $1369.575 \mathrm{~A}$ & $4.499 \mathrm{~A}$ & $1 \mathrm{~B}$ & $5.16 \mathrm{~A}$ & $15.05 \mathrm{~B}$ & $61.9 \mathrm{~B}$ \\
\hline WDR & $0.878 \mathrm{~B}$ & $62.30 \mathrm{~A}$ & $14.5125 \mathrm{~A}$ & $1180.075 \mathrm{~A}$ & $4.268 \mathrm{~A}$ & $2.125 \mathrm{AB}$ & $4.04 \mathrm{~A}$ & $13.87 \mathrm{~B}$ & $53.47 \mathrm{~B}$ \\
\hline Cultivar & NDVIR3 & $\mathrm{PH}$ & NN & LA & LAI & NPNS & LDM & SHDM & NS \\
\hline BR 16 & $0.89 a$ & $60.63 a$ & $15.06 \mathrm{a}$ & $1384.037 a$ & $5.380 \mathrm{a}$ & $2.581 \mathrm{a}$ & $4.71 \mathrm{a}$ & $21.23 \mathrm{a}$ & 78.19 a \\
\hline Embrapa 48 & $0.889 a$ & $55.72 \mathrm{a}$ & $13.66 \mathrm{~b}$ & $1278.263 \mathrm{a}$ & $4.974 \mathrm{a}$ & $1.96 \mathrm{~b}$ & $5.08 \mathrm{a}$ & $19.75 \mathrm{a}$ & $89.32 \mathrm{a}$ \\
\hline
\end{tabular}

*Means followed by the same capital letters (among water conditions) and the same lowercase letters (between cultivars) in the column do not differ significantly 


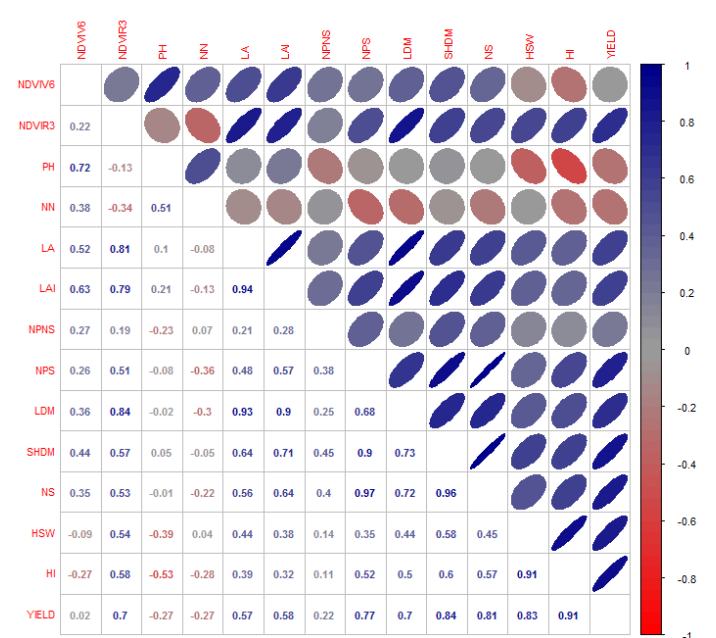

Fig 3. Correlation coefficient among morphological traits and yield components in soybean plants under different water deficit conditions. Crop seasons: $2013 / 2014$ and $2014 / 2015$. Londrina, PR. IRR (irrigated), NIRR (non-irrigated), WDV (water deficit induced in the vegetative stage), WDR (water deficit induced in the reproductive stage). NDVIV6 - Normalized Difference

Vegetation Index in the V6 stage; NDVIR3 - NDVI in the R3 stage; NPS - number of pods with seeds; HSW - 100-seed weight; HI - apparent harvest index; PH - plant height; NN - number of nodes; LA - leaf area; LAI - leaf area index; LDM - leaf dry matter; SHDM - shoot dry matter; NPNS - number of pods with no seeds; NPS - number of pods with seeds; NS - number of seeds; Yield.

Table 4. Morphological traits and yield components in the soybean cultivars Embrapa 48 and BR 16 under different water deficit conditions in the $2013 / 14$ crop season. Variables with no significant interaction (Cultivar $\mathrm{x}$ Water Condition)

\begin{tabular}{|c|c|c|c|c|c|c|c|c|c|c|c|c|c|}
\hline \multicolumn{14}{|c|}{ 2013/2014 } \\
\hline $\begin{array}{c}\text { Water } \\
\text { Condition }\end{array}$ & NDVIV6 & NDVIR3 & NN & LA & LAI & NPNS & NPS & LDM & SHDM & NS & HSW & $\mathrm{HI}$ & YIELD \\
\hline IRR & $0.860 \mathrm{~A}$ & $0.858 \mathrm{~A}$ & $14.88 \mathrm{~A}$ & $1441.47 \mathrm{~A}$ & $6.03 \mathrm{~A}$ & $0.889 \mathrm{~A}$ & $37.87 \mathrm{~A}$ & $4.68 \mathrm{~A}$ & $21.09 \mathrm{~A}$ & $82.13 \mathrm{~A}$ & $11.17 \mathrm{~A}$ & $0.434 \mathrm{~A}$ & $2857.23 \mathrm{~A}$ \\
\hline NIRR & $0.843 A B$ & $0.852 \mathrm{~A}$ & $14.98 \mathrm{~A}$ & $1204.92 \mathrm{AB}$ & $5.10 \mathrm{~A}$ & $2.212 \mathrm{~A}$ & $37.00 \mathrm{~A}$ & $4.25 \mathrm{~A}$ & $16.90 \mathrm{AB}$ & $72.2 \mathrm{~A}$ & $9.39 \mathrm{~B}$ & $0.397 \mathrm{~A}$ & 2018.87 B \\
\hline WDV & $0.803 \mathrm{C}$ & $0.701 \mathrm{C}$ & $15.21 \mathrm{~A}$ & $598.7 \mathrm{C}$ & $2.59 \mathrm{~B}$ & $1.812 \mathrm{~A}$ & $29.56 \mathrm{~A}$ & $2.43 \mathrm{~B}$ & $14.25 \mathrm{BC}$ & $61.27 \mathrm{AB}$ & $9.95 A B$ & $0.425 \mathrm{~A}$ & $1811.89 \mathrm{~B}$ \\
\hline WDR & $0.822 \mathrm{BC}$ & $0.775 \mathrm{~B}$ & $14.64 \mathrm{~A}$ & 1019.45 B & $4.05 \mathrm{AB}$ & $2.3 \mathrm{~A}$ & $22.91 \mathrm{~A}$ & $3.91 \mathrm{~A}$ & $11.03 \mathrm{C}$ & $43.8 \mathrm{~B}$ & $7.58 \mathrm{C}$ & $0.296 \mathrm{~B}$ & $1014.52 \mathrm{C}$ \\
\hline Cultivar & NDVIV6 & NDVIR3 & $\mathrm{NN}$ & LA & LAI & NPNS & NPS & LDM & SHDM & NS & $\mathrm{HSW}$ & $\mathrm{HI}$ & YIELD \\
\hline BR 16 & $0.834 \mathrm{a}$ & $0.793 \mathrm{a}$ & $14.97 \mathrm{a}$ & $1169.53 \mathrm{a}$ & $4.77 \mathrm{a}$ & $2.281 \mathrm{a}$ & $28.1 \mathrm{~b}$ & $3.97 \mathrm{a}$ & $15.27 \mathrm{a}$ & $61.39 \mathrm{a}$ & $9.64174 a$ & $0.385 \mathrm{a}$ & $1712.14 \mathrm{~b}$ \\
\hline Embrapa 48 & $0.83 a$ & $0.801 \mathrm{a}$ & $14.88 \mathrm{a}$ & $962.73 b$ & $4.12 \mathrm{a}$ & $1.325 \mathrm{~b}$ & $35.57 \mathrm{a}$ & $3.67 \mathrm{a}$ & $16.37 \mathrm{a}$ & $68.31 \mathrm{a}$ & $9.40765 a$ & $0.391 \mathrm{a}$ & 2139.11 a \\
\hline
\end{tabular}

*Means followed the same capital letters (among water conditions) and the same lowercase letters (between cultivars) in the column do not differ significantly by the Tukey test ( $p \leq 0.05$ ). NDVIVG - Normalized Difference Vegetation Index in the V6 stage; NDVIR3 - NDVI in the R3 stage; NN - number of nodes; LA - leaf area; LAI - leaf area index; NPNS - number of pods with no seeds; NPS - number of pods with seeds; LDM - leaf dry matter; SHDM - shoot dry matter; NS - 

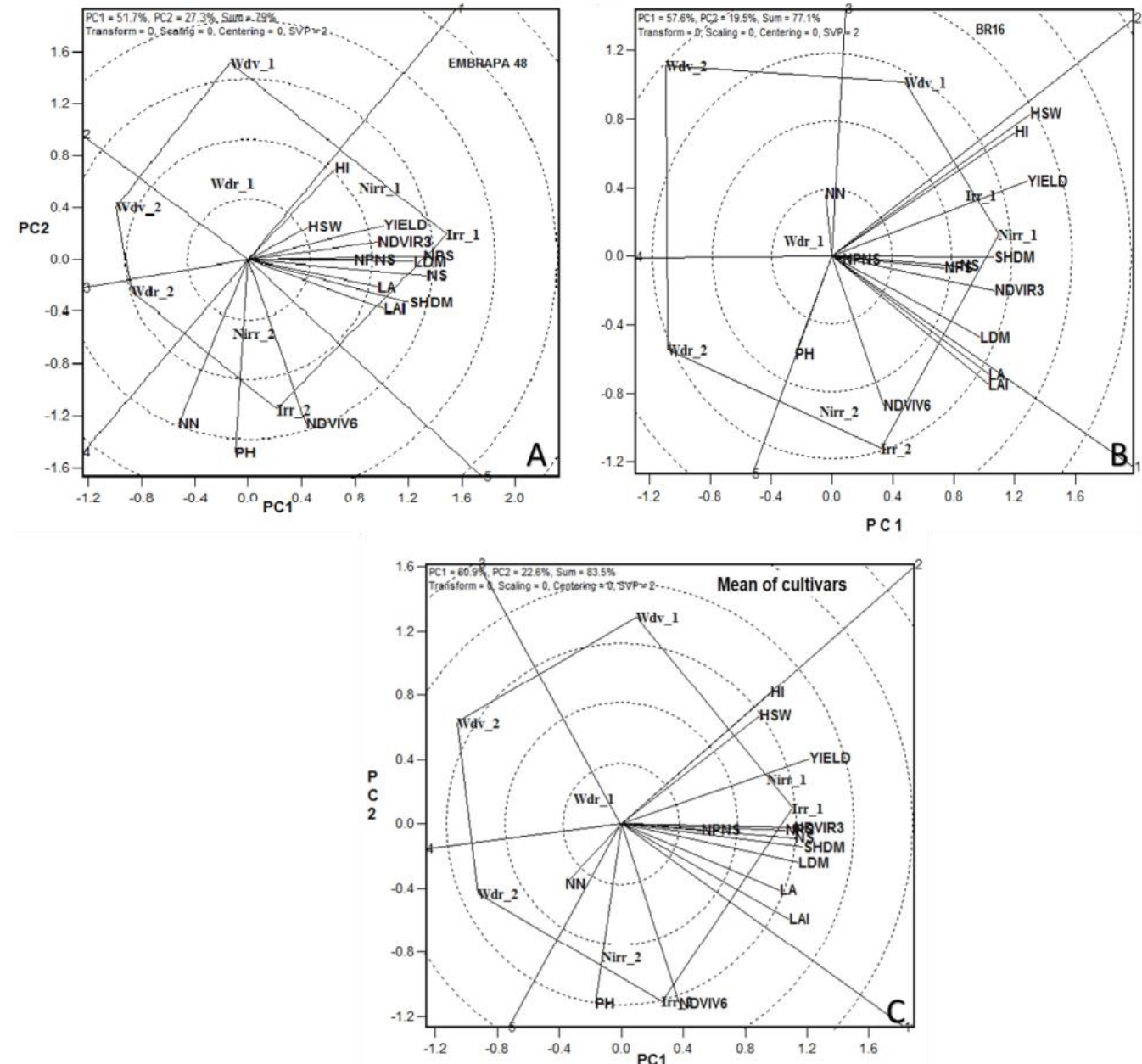

Fig 4. Principal Component Analysis (PCA) of morphological traits and yield components in the soybean cultivars Embrapa 48 (A), BR 16 (B), and the means of both cultivars (C) under different water deficit conditions in the 2012/13 and 2013/14 crop seasons. IRR (irrigated), NIRR (non-irrigated), WDV (water deficit induced in the vegetative stage), WDR (water deficit induced in the reproductive stage). NDVIV6 - Normalized Difference Vegetation Index in the V6 stage; NDVIR3 - NDVI in the R3 stage; NPS - number of pods with seeds; HSW - 100-seed weight; HI - apparent harvest index; PH - plant height; NN - number of nodes; LA - leaf area; LAI - leaf area index; LDM - leaf dry matter; SHDM - shoot dry matter; NPNS - number of pods with no seeds; NPS number of pods with seeds; NS - number of seeds; Yield. 
WDR and WDV treatments influenced most variables, which are associated with the IRR and NIRR sectors and in opposing sectors to WDV and WDR (Figure 4A, 4B and 4C).

In polygonal biplots, the concentric circle helps to visualize the length of vectors, in which traits with greater vectors have higher contribution and variances. Yield and $\mathrm{HI}$ were found in the fourth and in the third concentric circles, in BR 16 (Figure 4B) and Embrapa 48 (Figure $4 A$ ) cultivars, respectively. These findings indicate that such traits were more affected by WDV and WDR in BR 16 plants when compared to Embrapa 48 ones.

In both cultivars, HSW had a close relationship with grain yield (Figures $4 A, 4 B$ and $4 C$ ). The cultivar BR 16 showed greater variance, located in the fourth concentric circle (Figure 4B), while Embrapa 48 showed greater stability, located in the second circle (Figure 4A). On the other hand, NS varied more in Embrapa 48 (Figure 4A) than in BR 16 plants (Figure 4B) due to a greater NPS variance.

In relation to NDVI, when measured in the R3 stage (NDVIR3), such a trait was highly associated with yield, mainly in Embrapa 48 plants (Figure 4B). On the other hand, the traits NDVIV6, NN, and PH had no association with grain yield or other yield-related components. In addition, such variables are positioned in an opposite sector compared with WDV, thus showing greater influence of this water stress condition, mainly on Embrapa 48 plants. Water deficit had a negative effect on other growth traits (LA, LAI, LDM, and SHDM) in vegetative and reproductive stages.

\section{Discussion}

In this study, two soybean cultivars (BR 16 and Embrapa 48) with distinct susceptibility to water deficit (Oya et al., 2004; Carvalho et al., 2015) were characterized based on yield components and growth parameters. Water deficit was evaluated under four conditions - IRR, NIRR, WDV, and WDR. Multivariate statistics by PCA was performed to identify treatment combinations and traits with greater contribution to the observed variance.

Climate data from the water balance allowed us to infer on the real evapotranspiration, water deficit or surplus and the total of water withdrawn from the soil in each crop season (Figure S1). Rainfall and temperature variations reflected not only on the amount of available water, but also on the amount of water withdrawn by soybean plants. At high temperatures and low air humidity, a higher crop evapotranspiration is observed. Thus, even under WDV and WDR treatments, drought was more severe in the 2013/14 crop season (Figure S1). The stress index (SI) shows a greater intensity of water deficit when applied in 2013/14 (Figure 1), based on values equal to 0.167 and 0.455 , respectively, for water deficit induced in vegetative and reproductive stages in the 2012/13 crop season, and 0.366 and 0.645 for the same conditions in 2013/14. A more severe water deficit in 2013/14 made difficult to differentiate both cultivars for a large number of analyzed variables (Table 1 ).

Through PCA, reproductive and growth parameters were simultaneously evaluated under water deficit conditions (Figure $4 A, 4 B$ and $4 C$ ). This study performed an analysis of each cultivar independently (Figure $4 A$ and $4 B$ ), in order to identify differences among traits and in relationships established among them. This approach differs from most PCA studies performed under water deficit conditions, since they are only based on the joint analysis of different genotypes (Silvente et al., 2012). Mustafa et al. (2015) also applied PCA to classify maize (Zea mays L.) genotypes regarding drought tolerance, grouping 40 evaluated genotypes in four different groups.

In the present study, water deficit had a negative impact on soybean crop yield in both vegetative and reproductive stages (Tables 2 and 4). In the vegetative period, water deficit affected mainly the number of nodes and plant height. Desclaux et al. (2000) assessed the effect of drought on different development stages of soybean plants and observed that water deficit reduced plant height, so that the lowest plants were detected under drought induced in the vegetative stage.

In the present study, a negative drought effect was also observed in other growth parameters (LA, LAI, LDM, and SHDM) under WDV and WDR (Tables 3 and 4). Akinci and Lösel (2012) reported that drought reduced drastically root elongation and leaf expansion in soybean plants. In general, a greater reduction in leaf expansion occurs under drought, a condition in which partitioning in photosynthesis changes to increase the root-shoot ratio. In regards to NDVI, this parameter was strongly associated with yield when evaluated in the reproductive stage (R3) (Table 5). Carvalho et al. (2015) analyzed the NDVI of soybean plants under water deficit in the R5.5 stage and found an association between the results obtained for this parameter and physiological traits including photosynthesis, transpiration, and chlorophyll content. Although these authors stated that such a measurement is useful to evaluate responses of soybean cultivars to water deficit, they highlighted the importance of standardizing the development stage and leaf area for NDVI readings. A decrease in chlorophyll content is a typical symptom observed in plants under water deficit due to photo-oxidation of pigments and chlorophyll degradation. Chlorophyll content is the main component influencing NDVI, which explains the sensitivity of the in detecting differences a stress condition (Liu et al., 2012).

HSW was highly associated with yield in both cultivars (Figures 2A and 2B). Such a trait was the most affected by water deficit in the cultivar BR 16, which has greater seed weight than that of Embrapa 48 (Table 2). The latter has lighter seeds but in larger number than those of BR 16 plants, and showed more HSW stability under WDR (Figures $2 \mathrm{~A}$ and $2 \mathrm{~B}$ ), and, consequently, higher final yield. Similarly, Oya et al. (2007) also reported the difference in seed weight between such cultivars under water deficit in the reproductive stage.

Yield components showed differences for both development stages (vegetative and reproductive), with reduction in the number of pods and seeds and seed weight (Tables 2, 3 and 4). Differences were stronger in the reproductive stage, with final yield reduction by up to $60 \%$ (Table 2 and 4). Although water is important during the crop cycle, the reproductive period is the most critical phase (Nogueira and Nagai, 1988). A reduction in photosynthesis and stomatal conductance, besides retention of photoassimilates in vegetative structures, mainly in the stem, to the detriment of grains, occurs under water deficit (Ohashi et al., 2009). 
NPNS has no efficiency in the differentiation of genotype stability under stress conditions, which may be due to the number of seedless pods is high even under ideal conditions because of a high flower bud emission over plant capacity, thus generating empty pods.

When comparing the two cultivars in regards to grain yield, Embrapa 48 was the less sensitive to water deficit in the reproductive stage, which is considered, in general, the most severe (Table 2). On the other hand, BR 16 plants showed less sensitivity under WDV (Table 2). Drought tolerance in plants is a complex mechanism involving changes at morphological, physiological, and molecular levels that are activated according to the intensity, duration and stage in which drought is induced. Soybean genotypes have different strategies to deal with stress according to different situations. Drought-tolerant plants in a particular situation or stage may be drought-susceptible in others. DSI data confirm such differences in drought sensitivity between both cultivars, where BR 16 was more sensitive to WDR than Embrapa 48, while the opposite occurred in relation to WDV (Figure 2). Terra et al. (2015) found high correlation between DSI and several traits of interest in rice (Oryza sativa L.), showing that this index can be efficient for selecting tolerant genotypes under water deficit conditions. Du et al. (2009) used DSI to develop a soybean linkage map.

\section{Materials and Methods}

\section{Plant materials}

Two conventional soybean cultivars were evaluated - BR 16 and Embrapa 48, more and less sensitive to water deficit, respectively (Oya et al., 2004; Carvalho et al., 2015).

Experimental design and assaysExperiments were carried out in the 2012/13 and 2013/14 crop seasons at the Brazilian Agricultural Research Corporation National Soybean Research Center, located in Londrina,

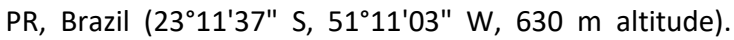
The experimental area was composed of a dystrophic Red Latosol (DRL) soil, with $71 \%$ clay content. The local annual average temperature is $21^{\circ} \mathrm{C}$, with the highest values in February $\left(28.5^{\circ} \mathrm{C}\right)$ and the lowest ones in July $\left(13.3^{\circ} \mathrm{C}\right)$. Annual rainfall is approximately $1600 \mathrm{~mm}$, with 123 days of showers annually, concentrated mainly from January to March.

The Köppen climate classification defines the location as Cfa (humid, subtropical, and with hot summers). The weather station located in the experimental area monitored temperature, relative humidity, and rainfall data. Temperature and rainfall data were used to calculate the water balance, according to Thornthwaite and Mather (1955) (Supplementary Fig S1).

In both crop seasons, experiments were carried out through a split-plot randomized block design, with four replicates. In plots, four water conditions were considered: irrigated (IRR), non-irrigated (NIRR), and water deficit induced in vegetative (WDV) and reproductive (WDR) stages. The two soybean cultivars (BR 16 and Embrapa 48) were distributed into subplots. Each subplot comprised eight rows, with $0.5 \mathrm{~m}$ spacing, and $5.5 \mathrm{~m}$ length per row, totaling 16 plants $\mathrm{m}^{-2}$.
Manual sowing was performed on November 5, in both crop seasons. Seeds were previously treated with fungicide and insecticide (carboxin $200 \mathrm{~g}+$ fipronil $250 \mathrm{~g}$ $100 \mathrm{~kg}^{-1}$ ) to prevent fungi and soil pest attacks. In-furrow inoculation with Bradyrhizobium japonicum strains SEMIA 5079 and SEMIA 5080 was performed, and fertilization was made based on soil analysis results.

\section{Water conditions}

To simulate stress by water deficit in vegetative and reproductive stages, rainout shelters moving on rails were used to cover plots when the rainfall begins and uncover them when it ends.

In the 2012/13 crop season, WDV started on December 5, 2012 and ended on December 27, 2012, while WDR started soon after the end of WDV, remaining until the harvesting period on March 05, 2013. In the 2013/14 crop season, WDV started on December 02, 2013 and ended on December 12, 2013, while WDR started soon after the end of WDV, remaining until the harvesting period on February 20, 2014.

Under NIRR condition, plants received natural rainfall, while under the IRR treatment the natural rainfall was complemented with irrigation when necessary. Pressure meters installed at $0.30 \mathrm{~m}$ deep in the field monitored the need for irrigation, activating it to maintain soil matric potential between -0.03 and $-0.05 \mathrm{MPa}$.

\section{Growth and yield traits}

Leaf area index (LAI), leaf area (LA), and leaf dry matter (LDM) were evaluated through an average of five plants per treatment in the R4 phenological stage (Fehr and Caviness, 1977). The following traits were evaluated in the R8 (harvest) stage: plant height $(\mathrm{PH})$, number of nodes (NN), number of pods with no seeds (NPNS), number of pods with seeds (NPS), shoot dry matter (SHDM), number of seeds (NS), 100-seed weight (g) (HSW), apparent harvest index ( $\mathrm{HI})$, and grain yield ( $\mathrm{kg}$ $\mathrm{ha}^{-1}$ ). All measurements were performed at the four central rows of each subplot.

The measurement of the Normalized Difference Vegetation Index (NDVI) in plants submitted to drought conditions is often performed from sensors attached to satellites. However, the increasing use of portable sensors in data acquisition has wide applicability in agricultural production, since it consists of a fast and nondestructive method, and is less susceptible to interference problems (Crusiol et al., 2016). Thus, NDVI readings were carried out in V6 (NDVIV6) and R3 (NDVIR3) phenological stages (Fehr and Caviness, 1977), using a GreenSeeker 505 handheld sensor, Ntech Industries, Inc (Ukiah, California, USA), at $0.80 \mathrm{~m}$ height above the canopy, following the methodology described by Carvalho et al. (2015).

\section{Drought susceptibility index}

The drought susceptibility index (DSI) was calculated according to Fischer and Maurer (1978), through the formula $D S I=\frac{\left[1-\left(\frac{Y S}{Y p}\right)\right]}{S I}$, where Ys is the genotype yield under stress; $Y p$ is the non-stressed genotype yield; and $\mathrm{SI}$ is the stress application intensity. 


\section{Statistical analysis}

The Shapiro-Wilk and Bartlett tests were used to check normality and homogeneity of variance at $p \leq 0.05$. Then, data were submitted to the analysis of variance (ANOVA) through the F-test $(p \leq 0.05)$. When $F$ values were significant, data were compared by the Tukey test. Data were standardized for the principal component analysis (PCA) to assure that all variables with distinct units would become dimensionless and with the same contribution. For the application of PCA and biplot graphs, a model based on the singular value decomposition (SVD) of principal components (PCs) for the present study was expressed as

$\frac{T_{i j k}-\bar{T}_{j k}}{s_{j k}}=\lambda_{1} \phi_{i k 1} \tau_{j k 1}+\lambda_{2} \phi_{i k 2} \tau_{j k 2}+\varepsilon_{i j k}$

where: $T_{i k j}$ is the mean value for the combination of crop season, water availability, and genotype; ij for the variable $k ; \bar{T}_{j k}$ is the mean value for the combination of crop season and treatment $i j$ for all genotypes; $\mathbf{S}_{j \mathrm{k}}$ is the standard deviation for the interaction of the treatment $j$ and the crop season $k$ among the means of genotypes; $\phi_{\mathrm{ik} 1}$ and $\phi_{\mathrm{ik} 2}$ are the PC1 and PC2 scores for the genotype $i ; \tau_{\mathrm{jk} 1}$ and $\tau_{\mathrm{jk} 2}$ are the PC1 and PC2 scores for the variable $j$; and $\varepsilon_{\mathrm{ijk}}$ is the residual effect associated with the model, with the interaction between genotype and crop season ( $i k$ ) in the variable $j$.

ANOVA and the Tukey test were performed through the ExpDes package of the $\mathrm{R}$ software (http://www.rproject.org). PCA was made through the GGEbiplot software.

\section{Conclusion}

Results from the present study indicate that water deficit affected soybean yield, mainly in the reproductive stage. PCA helped to identify the relationship among traits with greater contribution to explain total variance. In addition, PCA helped to assess treatments and agronomic and morphological traits simultaneously and to make inferences about their relationship. Embrapa 48 showed greater yield stability under WDR, while BR 16 showed to be more sensitive to such a condition, with seed weight highly affected by water deficit. Therefore, the relationship between weight and number of seeds was essential for distinguishing both cultivars under water deficit, since lighter seeds but in larger number were advantageous under water deficit induced in the reproductive stage. On the other hand, the largest leaf area of BR 16 plants may have led to a better recovery capacity when stress was induced in the vegetative stage. Thus, due to the difficulty in introducing all drought tolerance mechanisms in one genotype, breeding programs need to define selection parameters according to regional drought conditions.

\section{Acknowledgments}

We thank the Coordination for the National Council for Scientific and Technological Development (CNPq) for granting a scholarship to the authors WG (Master's student) and LCF (Postdoctoral fellow, Process \#503569/2012-7). This work was financially supported by the Brazilian Agricultural Research Corporation (Embrapa).

\section{References}

Akinci Ş, Lösel DM (2012) Plant water-stress response mechanisms. In: Rahman IMM, Hasegawa H (eds) Environmental sciences - water stress, 1st edn. InTech, Rijeka

Carvalho JFC, Crusiol LGT, Perini LJ, Sibaldelli RNR, Ferreira LC, Marcelino-Guimarães FC, Nepomuceno AL, Neumaier N, Farias JRB (2015) Phenotyping soybeans for drought responses using remote sensing techniques and non-destructive physiological analysis. GI Sci Technol. 8:1-16.

Crusiol LGT, Carvalho JFC, Sibaldelli RNR, Neiverth W, Rio A, Ferreira LC, Procopio SO, Mertz-Henning L.M., Nepomuceno AL, Neumaier N, Farias JRB (2017) NDVI variation according to the time of measurement, sampling size, positioning of sensor and water regime in different soybean cultivars. Precis Agric. 4:470-490.

Dai A (2013) Increasing drought under global warming in observations and models. Nat Clim Change. 3:52-58.

Desclaux D, Huynh T, Roumet P (2000) Identification of soybean plant characteristics that indicate the timing of drought stress. Crop Sci. 40:716-722.

Du W, Wang M, Fu S, Yu D (2009) Mapping qtls for seed yield and drought susceptibility index in soybean (Glycine max L.) across different environments. J Genet Genomics. 36:721-731.

Fehr WR, Caviness CE (1977) Stages of soybean development. SREC special report 80, lowa State University, Ames, p 1-12

Fischer RA, Maurer R (1978) Drought resistance in spring wheat cultivars I. Grain yield response. Aust J Agric Res. 29:897-907.

IPCC - Intergovernmental Panel on Climate Change (2014) Summary for policymakers. In: Pachauri RK, Meyer LA, (eds) Climate change 2014: Synthesis report. Contribution of working groups I, II and III to the fifth assessment report of the intergovernmental panel on climate change. IPCC, Geneva, Switzerland, $p$ 151

Khalili M, Naghavi M, Pour-Aboughadareh A, Rad NH (2013) Effects of drought stress on yield and yield components in maize cultivars (Zea mays L.). Intl J Agron Plant Prod. 4:38-49.

Kron AP, Souza GM, Ribeiro RV (2008) Water deficiency at different developmental stages of Glycine max can improve drought tolerance. Bragantia. 67:43-49.

Ku YS, Au-Yeung WK, Yung YL, Li MW, Wen CQ, Liu X, Lam HM (2013) Drought stress and tolerance in soybean. In: Board JE (ed) A comprehensive survey of international soybean research - genetics, physiology, agronomy and nitrogen relationships, 1st edn. InTech, Rijeka. 
Liu J, Pattey E, Jégo G (2012) Assessment of vegetation indices for regional crop green LAl estimation from landsat images over multiple growing seasons. Remote Sens Environ. 123:347-358.

Mustafa HSB, Farooq J, Hasan E, Bibi T, Mahmood T (2015) Cluster and principle component analyses of maize accessions under normal and water stress conditions. J Agr Sci. 60:33-48.

Nogueira SS, Nagai V (1998) Deficiência hídrica simulada nos diferentes estádios de desenvolvimento de um cultivar precoce de soja. Bragantia. 47:9-14.

Ohashi Y, Saneoka H, Fujita H (2009) Differences in the responses of stem diameter and pod thickness to drought stress during the grain filling stage in soybean plants. Acta Physiol Plant. 31:271-277.

Oya T, Nepomuceno AL, Neumaier N, Farias JRB, Tobita $S$, Ito O (2004) Drought tolerance characteristics of Brazilian soybean cultivars - evaluation and characterization of drought tolerance of various Brazilian soybean cultivars in the field. Plant Prod Sci. 7:129-137.

Rolla AAP, Carvalho JFC, Fuganti-Pagliarini R, Engels $C$, Rio A, Marin SRR, Oliveira MCN, Beneventi MA, Marcelino-Guimarães FC, Farias JRB, Neumaier $N$, Nakashima K, Yamaguchi-Shinozaki K, Nepomuceno AL (2014) Phenotyping soybean plants transformed with rd29A:AtDREB1A for drought tolerance in the greenhouse and field. Transgenic Res. 23:75-87.

Silvente A, Sobolev A, lara M (2012) Metabolite adjustments in drought tolerant and sensitive soybean genotypes in response to water stress. PLoS One 7:111.
Stolf-Moreira R, Medri ME, Neumaier N, Lemos NG, Pimenta JA, Tobita S, Brogin RL, Marcelino-Guimarães FC, Oliveira MCN, Farias JRB, Abdelnoor RV, Nepomuceno AL (2010) Soybean physiology and gene expression during drought. Genet Mol Res. 9:19461956.

Terra TGR, Leal TCAB, Rangel PHN, Oliveira AB (2015) Características de tolerância à seca em genótipos de uma coleção nuclear de arroz de terras altas. Pesq Agropec Bras. 50:788-796.

Thornthwaite CW, Mather JR (1955) The water balance. Drexel Institute of Technology - Laboratory of Climatology, Centerton.

USDA - United States Department Of Agriculture (2016) Foreign agricultural service. Production, supply and distribution online: Custom query. USDA

Wu N, Guan Y, Shi T (2011) Effect of water stress on physiological traits and yield in rice backcross lines after anthesis. Energy Procedia. 5:255-260. 